\title{
FORMING PRACTICAL COMPETENCE IN HEALTH PROMOTION
}

\author{
K. Kostov ${ }^{1 *}$, H. Milcheva ${ }^{2}$, S. Kyuchukova ${ }^{3}$ \\ ${ }^{1}$ Branch Haskovo, Trakia University, Haskovo, Bulgaria \\ ${ }^{2}$ Medical College, Trakia University, Stara Zagora, Bulgaria \\ ${ }^{3}$ Department of Health Care, Trakia University, Stara Zagora, Bulgaria
}

\begin{abstract}
Introduction. Health as a valuable and vital human need is determined by a number of factors that have their economic, political, ethical, social and medical measurability. It is the right and responsibility of both the individual and society as a whole in the context of European health strategy in the 21 st century based on " literacy" for health . For the realization of some of its preventive aspects it is necessary during the process of university education practical competencies in Health promotion to be formed in students with medical specialties.

The purpose. A research has been conducted to establish the role of the subject and the individual work of students in Health promotion to form their practical competence. We made a research amongst students from the first to the last year of their training in different medical specialties: nurses, midwives, rehabilitation therapist, medical laboratory assistants.
\end{abstract}

Methods. Following methods were used: questionnaire, documentary, direct observation, mathematical-statistical method, desk research.

Conclusion. The students of medical specialties have acquired applicable practical skills and have enriched their knowledge and skills in respect of promotional activity by individual work for developing programs for prevention of behavioral risk factors in Health promotion.

Key words: health promotion, students, competencies, promotive activity.

\section{INTRODUCTION}

Health is a vital human need, but in modern times this need grew into a value from medical, social, economic, ethical, legal, political and international point of view. Health is a necessity, but it is also a human right - the right to a good life, fulfillment and development.

"Literacy" for health is an element of European health policy in the 21 st century.

Health and its determinants - both for the individual and the society as a whole - is becoming more and more significant as social economic factor, as a personal and public value, a right and responsibility of each and everyone. Perfect health, however, is fighting for a "new standard". It pursues something

*Correspondence to: Kosta Kostov, Branch

Haskovo -Trakia University, Haskovo ,48

Syedinenie Boul., Bulgaria, +359888927676,

kostov@uni-sz.bg more than the absence of disease and seeks higher levels of expression by "health promotion."

Health care is not only the responsibility of the health sector; it goes far beyond its borders towards the style and quality of life, including social, organizational, pedagogical and political processes (1). As L.Griyn emphasizes, the health promotion is one of the few interdiscipline initiatives in health care, which is searching for a real relief from the domination of medicine (2).

In English literature the concept of a "HPpractitioner", defined as a person who is competent to work to promote health and reduce health inequalities, following the principles of health promotion to build healthy public policy, creating supportive environments, strengthening of public activities, building personal skills and knowledge, and the reorientation of health activities to cross-sectoral cooperation and partnership $(3,4)$. 
Competence is the state or property of individuals, enabling them to cope with the complex task of reaching a certain standard. Competence includes knowledge, skills, attitudes and perceptions of the performance of some activity (5). Competencies in health promotion are needed for persons of different occupations (specialists in public health, social and political sciences, pedagogy, psychology, etc.). Working in partnerships for health promotion and creating a healthy living environment $(3,4)$. Considering the complexity of the concept of competence we analyzed the curriculum for medical professionals with a degree "Bachelor" and found that they learn a large number of subjects that develop skills in promotive activities. Such academic subjects are: Health Promotion; Philosophy and introduction to nursing care; Practical foundations of nursing; Prevention of risk factors in pregnant; Medical Psychology; Childhood pedagogy and Psychology; Principles and methods of health education; Communication skills; Social Medicine; Medical ethics and deontology; Social and health legislation.

Based on the existing Bulgaria legislation, regulating the professional activities of medical professionals, we revealed that university medical education form new competences in healthcare professionals for promotive, health educational and preventive activities within the medical team and alone (6). New competences of learning medical professionals enable them to: assessment of health status and medical and social needs of the patient's family and community, taking into account their health culture; planning, initiation and taking quality continuous care, according the needs; formation of communication skills in order to: counseling, counseling on issues concerning preservation of the patient's health, professional communication with members of the medical team; planning and implementation of promotional and preventive programs; implementation of health training for health education; self-assessment activities in compliance with the standards of good health care in the performance of health care and economic dimensions; attitudes for continuing education, professional development and participation in researches.

The purpose of this study was to determine the role of the course and individual work in
Health promotion for the formation of practical skills in students of medical specialties.

The tasks performed to achieve the goal:

- Students moderators developed programs for prevention of behavioral risk factors in the discipline of Health promotion

- Developed and distributed was a questionnaire containing nine open and closed questions through which they got information about satisfaction and opinion of the students for their training in the discipline of Health promotion.

- The received unique information was mathematically and statistically processed.

- The results were summarized and analyzed, and conclusions were formulated about the importance of students' individual work for the development of programs for prevention of behavioral risk factors in the discipline of Health promotion and the level of acquired competencies and skills in this area.

Studied contingent: 60 people were interviewed, students of medical specialties Nurse (19), Midwife (9), Rehabilitation therapist (20), Medical laboratory assistant (12) at Faculty of Medicine, Trakia University in Stara Zagora.

Period of conducting the survey: JanuaryMarch 2014.

Methods: questionnaire, documentary, direct observation, mathematical statistics, Desk research.

In line of European health policy in the 21st century the "Literacy" for health is element which focuses on learning and teaching of the discipline of Health promotion. Each medical specialty has set in its methods of training the promotional element in medicine and holistic care for the patient. As A.Andonova stated in her monograph "Main concern is the holistic care of people. The focus of nursing is promotion of health, maintenance, treatment, recovery and support."(7). Students had to focus in these characteristics of medical practice in their extracurricular solo work when preparing a program for the prevention of behavioral risk factors in the discipline of Health promotion. This is required after they complete the theoretical and practical training on the target subject.

In analyzing the results of the questionnaire we found a link between the answers to some questions. This is between the first (see Table 1 ) and the third (see Table 2) question. 
Table 1. Impact of discipline

\begin{tabular}{|ll|r|r|r|}
\hline Qestion № 1 & Number & \% & Valid \% \\
\hline \begin{tabular}{ll|r} 
Do you think that the \\
content of the course
\end{tabular} Totally disagree (1) & 0 &, $0 \%$ &, $0 \%$ \\
"Health Promotion" has & Rather disagree (2) & 2 & $3,4 \%$ & $3,4 \%$ \\
increased your professional & Disagree (1+2) & $\mathbf{2}$ & $\mathbf{3 , 4}$ & $\mathbf{3 , 4}$ \\
competence? & neutral (3) & 8 & $13,6 \%$ & $13,6 \%$ \\
& Rather agree (4) & 18 & $30,5 \%$ & $30,5 \%$ \\
& Totally agree (5) & 31 & $52,5 \%$ & $52,5 \%$ \\
& Agree (4+5) & $\mathbf{4 9}$ & $\mathbf{8 3 , 1}$ & $\mathbf{8 3 , 1}$ \\
& Total & 59 & $100,0 \%$ & $100,0 \%$ \\
\hline
\end{tabular}

$* * *$ Valid $\%$ - percentage of responses after subtracting the number of those who didn't respond.

Combination of fourth and fifth response shows that over $83 \%$ of respondents agree that the content of the course "Health Promotion" increased professional competencies. And only $3.4 \%$ disagree with this statement. This allows us to claim that the discipline program that the students follow is well structured and serves its purpose to educate students in preventive and promotive health activities and at the same time it increases and builds their professional competence.

As an innovative and interactive method of teaching the discipline we use extracurricular independent work of students as they prepare programs for the prevention of behavioral risk factors and then they present it. In this connection, the following question was asked in the questionnaire - Table 2.

Table 2. Making coursework

\begin{tabular}{|c|c|c|c|c|}
\hline \multicolumn{2}{|c|}{ Question № 3} & Number & $\%$ & Valid \% \\
\hline \multirow{8}{*}{$\begin{array}{l}\text { Was it helpful to do a } \\
\text { coursework in "Health } \\
\text { Promotion"? }\end{array}$} & Unimportant (1) & 0 &, $0 \%$ & $0 \%$ \\
\hline & Not very important(2) & 4 & $6,7 \%$ & $6,7 \%$ \\
\hline & Not important $(1+2)$ & 4 & 6,7 & 6,7 \\
\hline & Important enough (3) & 20 & $33,3 \%$ & $33,3 \%$ \\
\hline & Very important (4) & 19 & $31,7 \%$ & $31,7 \%$ \\
\hline & Extremely important (5) & 17 & $28,3 \%$ & $28,3 \%$ \\
\hline & Important $(3+4+5)$ & 56 & 93,3 & 93,3 \\
\hline & Total & 60 & $100,0 \%$ & $100,0 \%$ \\
\hline
\end{tabular}

Over $93 \%$ of respondents think that preparation of coursework in the subject "Health Promotion" was something useful and important, and only $6.7 \%$ think the opposite. The first group of respondents found positive aspects and significant personal benefits of self-work, they have perfected in: working with the book, the judgment of open information, structuring a presentation, work in medical web sites, etc.
Considering the positive attitude of the students and to calculate the statistical indicators of the two discussed above questions (Question 1 and Question 3) we set a numerical value (factor) for each of the possible answers. We gave the highest value (5) to the most positive response, respectively, the lowest (1) to the most negative which is shown in Table 3.

Table 3. Professional competence

\begin{tabular}{|c|c|c|}
\hline & $\begin{array}{l}\text { Question № } 1 \\
\text { Do you think that the content of the } \\
\text { course "health promotion" has } \\
\text { increased your professional } \\
\text { competence? }\end{array}$ & $\begin{array}{l}\text { Question № } 3 \\
\text { Was it helpful doing coursework } \\
\text { in "Health Promotion"? }\end{array}$ \\
\hline Valid answer & 59 & 60 \\
\hline Did not answer & & 0 \\
\hline Arithmetic average & 4,32 & 3,82 \\
\hline Median & 5,00 & 4,00 \\
\hline Trend & 5 & 3 \\
\hline
\end{tabular}


It shows that the average value of magnitude "Improving the professional competence is the result of discipline" is 4.32. The trend or the most common numeric value that is observed among the many students of the set is a 5 - this is the main significance of magnitude. The results clearly show the attitude of students who rather believe that the content of the course "Health promotion" increased their professional competence.

The average value of magnitude "Usefulness of the development of coursework in discipline issue" is 3.82. The trend or the most common numeric value that is observed among the many students of the set is 3 - this is the main significance of magnitude. The results suggest that students take the coursework in "Health Promotion" as something important.

To find out how practicable and close the topics of these course works are to the students we put the following question in the questionnaire Which one of the proposed topics is most closely related to your practical work? (Table 4)

Table 4. Topics for self employment

\begin{tabular}{|l|r|r|r|}
\hline \multicolumn{1}{|c|}{ Question № 2 } & Numbe & \multicolumn{1}{c|}{ r } & Valid \% \\
\hline$\underline{\text { Topics }}$ & 11 & $18,3 \%$ & $18,6 \%$ \\
& & \\
1. Concept for health promotion. Modern concepts and definitions of & 9 & $15 \%$ & $15,3 \%$ \\
health. & 9 & $15 \%$ & $15,3 \%$ \\
2. Approach to solving the health problems of the population. & $\mathbf{1 4}$ & $\mathbf{2 3 , 3 \%}$ & $\mathbf{2 3 , 7 \%}$ \\
3. Environment and health. & 10 & $16,7 \%$ & $16,9 \%$ \\
4. Health motivation and healthy lifestyle. & $\mathbf{1 4}$ & $\mathbf{2 3 , 3 \%}$ & $\mathbf{2 3 , 7 \%}$ \\
5. Promotion of health and some behavioral risk factors. & \\
6. Role of medical professionals in health promotion &
\end{tabular}

*** One respondent did not indicate any of the possible answers. The total of the percentages exceeds $100 \%$ because some students gave more than one topic as closely related to their practical activities.

The results show that most of the respondents accept topics "Health motivation and healthy lifestyle" and "Role of health professionals in health promotion" - respectively $23.7 \%$ think topics are close to them and practicable in their medical practice. The follow topics are "Concept of health promotion. Modern concepts and definitions of health"(18.6\%) and "Health promotion and some behavioral risk factors"(16.9\%) Finally, respondents put "Approach to solving the health problems of the population" and "Environment and health" with $15.3 \%$ of the answers. The gradation of the topics showed that students of medical specialties have the mindset and culture to apply their professional competencies in the first place to motivate and appeal to a healthy lifestyle followed by finding ways to prevent some behavioral risk factors and health promotion, and finally, they would solve the health problems of the population and the providing appropriate living environment. In line with this, they clearly understand their important role of moderators medical professionals in health promotion.

In conclusion, we can summarize that students of medical specialties through their self- work creating programs for prevention of behavioral risk factors in the discipline of Health promotion have acquired skills and enriched their knowledge and skills in this area. This determines a new platform for activities and a challenge to health care professionals to be actively involved in health promotion.

\section{CONCLUSIONS}

1. The training of medical specialists in Health promotion formed their practical skills and increases their activity in the implementation of various preventive programs.

2. Students of these specialties are clearly aware of their important role as promoters of health and their function as moderators.

4. Acquired practical skills determine a new area of activity in health promotion and positive experience that can be included in personal $\mathrm{CV}$ students.

\section{REFERENCES}

1. Mladenova, S., Health Education, 2001 Artic, S. , 2009, .120

2. Borisov, V., S.Popova , Health Promotion , S., Arso , 1998, p. 120

3. Barbara Battel-Kirk, M argaret M. Barry, Alison Taub, Linda Lysoby, 2009. A review of the international literature on health promotion competencies: identifying frameworks and core competencies. Global Health Promotion. Vol.16 № 2, 12-20

4. Dempsey C., B. Battel-Kirk, M. Barry and the Comp HP Proj

5. Marinova, P. , Professional competence and competencies. Technological guidance for the development of the competence of health care professionals. Health Management vol.4, № 2,2004, p.25-28

6. Official Gazette, issue 50/01.07.2011

7. Andonova , A. , Training of nurses . Role of motivation, monograph, Stara Zagora, 2013, p.102 
KOSTOV K., et al. 